九州大学学術情報リポジトリ

Kyushu University Institutional Repository

\title{
Optimal Use of Pesticides for Controlling Insect Pests in Apple Orchards
}

Seo, Mi Ja

Department of Applied Biology, College of Agriculture and Life Sciences, Chungnam National University

Jin, Na Young

Department of Applied Biology, College of Agriculture and Life Sciences, Chungnam National University

Lee, You Kyoung

Department of Applied Biology, College of Agriculture and Life Sciences, Chungnam National University

Jun, Jun Hack

Department of Applied Biology, College of Agriculture and Life Sciences, Chungnam National University

他

https://doi.org/10.5109/1526396

出版情報：九州大学大学院農学研究院紀要. 60 (2)，pp.363-370，2015-09-18. Faculty of Agriculture, Kyushu University

バージョン :

権利関係 : 


\title{
Optimal Use of Pesticides for Controlling Insect Pests in Apple Orchards
}

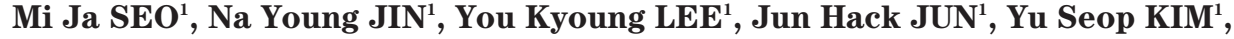 \\ Bo Ram LEE ${ }^{1}$, Young Shin KIM ${ }^{2}$, Chi Hwan LIM ${ }^{2}$, Young Nam YOUN ${ }^{1}$, \\ Chisa YASUNAGA-AOKI* and Yong Man YU ${ }^{1 *}$
}

\author{
Laboratory of Insect Pathology and Microbial Control, Institute of Biological Control, \\ Faculty of Agriculture, Kyushu University, Fukuoka 812-8581, Japan \\ (Received May 7, 2015 and accepted May 19, 2015)
}

\begin{abstract}
In considering the possibility of controlling the spray volume of pesticides according to cultivation period, actual spray volumes for controlling insect pests were investigated in an apple orchard in the city of Gongju in Chungnam province. Before the flowering period, a spray volume of 372 1/10 a was sprayed in the middle of April, whereas 449-452 1/10 a was sprayed from June to August when the leaves and fruit were luxuriate. Though 372 1/10 a, much less than the standard spray volume, was used for controlling moths around the middle of April, more than the amount of the active ingredients sufficient for $\mathrm{LC}_{95}, 0.018 \mathrm{~kg}$ a.i. $/ 10 \mathrm{a}$, was attached in all treated plots. In mid-July and late August, however, the standard spray volume, 450 1/10 a was sprayed, but the amount of the active ingredients in several plots was less than that inquired for $\mathrm{LC}_{95}$. This result showed that it was impossible to increase the treatment efficiency of the active ingredients by simply increasing spray volumes. It was identified that the more the amount of the active ingredients (kg a.i) per unit area $(10 \mathrm{a})$ was, the better were the control effects against insect pests. Regarding the results of using insecticide spray to control aphids, A. citricola in the middle of June, the amounts of the active ingredients in several plots were under $0.010 \mathrm{~kg}$ a.i./10 a for $\mathrm{LC}_{95}$ so that less than $80 \%$ of the control value was shown after seven days of treatment. However, with the exception of three plots, all other plots that were sprayed with more a larger amount of the active ingredients and showed a $100 \%$ control value against $A$. citricola.
\end{abstract}

Key words: Amount of active ingredients, Apple, Cultivation time, Insecticide, Spray volume

\section{INTRODUCTION}

Crops that are used as food for humans have been protected by humans against external invaders for several hundred or several thousand years through diverse methods. Agricultural products that had been insufficiently available began to rapidly increase in the 1950s thanks to the development and use of chemical pesticides. These pesticides are essential agricultural materials that can improve the productivity and quality of agricultural products as well as increases the storability of agricultural products (Ihm et al., 2003). However, recently, due to the problem of environmental hazards along with consumers' demands for safe agricultural products, measures to prevent pesticide abuse, reduce the amounts used, and replace pest control agents have been continuously reviewed. Accordingly, the amount of pesticides used per the unit area of fruit farms has been gradually decreasing. In the case of apple orchards, whereas approximately $22.1 \mathrm{~kg}$ a.i/ha of pesticides was used in 2002 according to the results of a survey in 2002 , approximately $11.7 \mathrm{~kg}$ a.i/ ha of pesticides was used in 2010 according to the results of a survey in 2010, indicating that the amount of pesti-

Department of Applied Biology, College of Agriculture and Life Sciences, Chungnam National University, Daejon 305-764, Korea

${ }^{2}$ Department of Bio Environmental Chemistry, College of Agricultural Biology \& Life Science, Chungnam National University, Daejeon 305-764, Korea

* Joint corresponding authors (E-mail: youngnam@cnu.ac.kr; yasunaga@grt.kyushu-u.ac.jp) cide used per the unit area had decreased by approximately 50\% over the eight years (Ihm et al., 2003; Ha et al., 2012). However, the largest problem recently is that most farms do not consider the problem of developed resistance formed due to pesticide abuse resulting from inappropriate pesticide spraying methods. As a result, sufficient disease and insect pest control effects are not achieved even after spraying pesticide in some cases, and some farms imprudently increase the concentrations of pesticides or increase the amount and times of spraying without observing the guidelines for the safe use of pesticides

The effects of pesticides rely on their characteristics of use which vary with the spraying tools, spraying methods, crop cultivating methods, and characteristics of chemicals used. The characteristics of use show clear differences according to users' skill levels. Although the effects of pesticides increase in proportion to increases in the amount of chemicals used, increases in the amount of chemicals used exceeding the appropriate concentration do not affect the effects of pesticides (Jeong et al., 2004). Therefore, insect pest control effects cannot actually be expected from increases in the concentration of pesticides used or the volume of pesticides sprayed. In the case of the volumes sprayed, safe pesticide spraying methods are presented according to kind of crop under the criteria for pesticide registration and tests. However, pesticide abuse results because the standards for the appropriate volumes of pesticides to be sprayed per the unit area have not been accurately set, and increases in the amounts of pesticides used are causing distrust among 
consumers. In the case of South Korea, the standard volumes of pesticides to be sprayed per unit area have been determined according to kind of crop regardless of cultivation time or the time of occurrence of insect pests, such as 4,500 1/ha for apples. Therefore, in many cases, farms do not consider the appropriate volumes of pesticides to be sprayed per unit area when they spray pesticides. The results of a survey of problematic insect pests in apple orchards and the actual state of control reported by Lee et $a l$. (2007) show the average volume of pesticides sprayed per the unit area to be $3601 / 10$ a, which is less than the standard volume. In addition, the effects of pesticides may also vary with the types of sprayers or nozzles used to spray the pesticides. Therefore, the standardization of optimum spraying methods is critical so that any unskilled fruit farmers can evenly spray chemicals with the appropriate volumes of pesticides. According to the results of an analysis of the state of the use of pesticides by fruit farms in 2004, 73\% of fruit farms used speed sprayers (SSs) to spray pesticides (Lee et al., 2007).

Therefore, in the present study, the volumes and methods of spraying pesticides were surveyed at a farm that was using the SSs that are used by at least 70\% of apple orchards to control insect pests, and the relationships between the amounts of active ingredients per unit area according to the volumes of pesticides sprayed and insect pest control effects were evaluated to consider the possibility of adjusting the volumes of pesticides sprayed according to cultivation time and the patterns of occurrence of insect pests.

\section{MATERIALS AND METHODS}

\section{Monitoring of the occurrence of insect pests such as moths and aphids in apple orchards}

Tests for identifying the volumes of pesticides to be sprayed for the optimum efficacy of pesticides were con- ducted from April through September of 2014 in an apple orchard with a size of 66.116 a (2,000 pyeong) in Shinpung-myeon, Gongju-si, Chungcheongnam -do. The apple species was Fuji and 18 year-old trees and seven-year-old trees had been planted in different areas. Approximately 18 year-old, 120 trees had been planted per 10 a and approximately seven year-old, 90 trees had been planted per 10 a. For moth forecasting surveys, pheromone delta traps for six species of fruit trees from Green-Agrotech Co., Ltd., which are materials for insect pest control, were installed at the end of March to periodically monitor moth pests. Grapholita molesta and Phyllonorycter ringoniella were captured at an average density of four per trap and identified in early April and thereafter. The flypaper of the traps was replaced at intervals of two weeks, and the lures were replaced at intervals of one month to maintain capture efficiency. The occurrence of aphids and mites was identified through visual investigations. At least 50 of A. citricola appeared per survey plot starting from the middle of June. Therefore, a chemical spray test was conducted. Four on average and up to $48 G$. molesta and $P$. ringoniella were captured per pheromone trap at the end of July and at the end of August when the occurrence of these insects normally increases. Therefore, two additional chemical spray tests were conducted to control the moths.

\section{Survey of the actual state of the use of pesticides and spray methods according to cultivation time}

In the test farm, the cultivating farmer sprayed chemicals firsthand using an SS (HANSUNG T\&I Co., Ltd.) loaded with a $500 \mathrm{l}$ tank, and the chemicals sprayed, volumes sprayed, spraying time, and spraying methods such as spray velocity and pressure varied according to cultivation time. The spraying methods according to day of spraying are presented in Table 1. Through insect pest occurrence condition surveys that began at the end of

Table 1. Actual conditions of insecticide use for controlling of insect pests in the apple orchard in Chungnam province

\begin{tabular}{|c|c|c|c|c|}
\hline & Mid-April & Mid-June & Late July & Late August \\
\hline Test insecticide & $\begin{array}{l}\text { acatamiprid } 8 \% \\
\text { WP }\end{array}$ & $\begin{array}{c}\text { acetamiprid } 2.5 \% \\
\text { etofenprox } 8 \% \\
\text { WP }\end{array}$ & $\begin{array}{l}\text { dinotefuran } 20 \% \\
\text { WG }\end{array}$ & $\begin{array}{l}\text { thiodicarb } 40 \% \\
\text { WP }\end{array}$ \\
\hline Target pests & P. ringoniella & A. citricola & $\begin{array}{l}\text { G. molesta } \\
\text { P. ringoniella }\end{array}$ & $\begin{array}{l}\text { G. molesta } \\
\text { P. ringoniella }\end{array}$ \\
\hline Standard spray volume & \multicolumn{4}{|c|}{ 450L/10 a standard spray volume in apple by speed sprayer } \\
\hline $\mathrm{kg}$ a.i in $450 \mathrm{l} / 10 \mathrm{a}$ & 0.018 & 0.011 & 0.090 & 0.180 \\
\hline $\begin{array}{l}\text { Spray volume }(\mathrm{L}) \\
/ \mathrm{kg} \text { a.i } / 10 \text { a for } \mathrm{LC}_{95}\end{array}$ & $400 / 0.016$ & $400 / 0.010$ & $400 / 0.080$ & $400 / 0.160$ \\
\hline Actual spray volume (1/10 a) & 372 & 452 & 449 & 452 \\
\hline $\begin{array}{l}\text { Actual amount of active ingredient } \\
(\mathrm{kg} \text { a.i } / 10 \mathrm{a})\end{array}$ & 0.015 & 0.011 & 0.090 & 0.181 \\
\hline $\begin{array}{l}\text { Standard spraying time (min/10 a) } \\
\text { by SS }\end{array}$ & \multicolumn{4}{|c|}{$6 \mathrm{hr} / 4 \mathrm{ha} / 1$ day (9 min/10 a) } \\
\hline Actual Spraying time (min/10 a) & 18 & 23 & 25 & 28 \\
\hline $\begin{array}{l}\text { Spraying speed (level) } \\
\text { and pressure (rpm) }\end{array}$ & $\begin{array}{c}\text { low speed level } 2-3 \\
\sim 2,000\end{array}$ & $\begin{array}{c}\text { low speed level } 2-3 \\
2,000 \sim 2,500\end{array}$ & $\begin{array}{l}\text { low speed level } 2-3 \\
2,500\end{array}$ & $\begin{array}{c}\text { low speed level } 2-3 \\
2,500\end{array}$ \\
\hline
\end{tabular}


March, the occurrence of the insect pests, $G$. molesta and $P$. ringoniella was identified using the pheromone traps starting in early April. Therefore, pesticides had begun to be sprayed in the middle of April. Thereafter, through pheromone traps and periodic forecasting based on visual investigations, the occurrence of $A$. citricola was identified in the middle of June, and increases in the density of captured moth pests were identified in the middle of July and at the end of August. Therefore, additional pesticide sprays were conducted in the middle of June, in the middle of July, and at the end of August.

\section{Spray methods and control effects against moths and $A$. citricola}

Water sensitive paper $(52 \times 76 \mathrm{~mm}$, TeeJet Tech, Switzerland) and patches were used to check the degree of pesticide spray. The water sensitive paper was installed by attaching it to or hanging it using hooks on branches and leaves at many points on the plantation to check the degree of uniform spray of pesticides and was used to judge whether pesticides were appropriately attached after pesticide spray based on the degree of coating on the water sensitive paper. $\alpha$-cellulose paper (Whatman 17CHR, $46 \times 57 \mathrm{~cm}$, Cat. No. 3017-915) that is made and used as patches for skin exposure measurement to evaluate the amounts of active ingredients of pesticides per unit area was cut into pieces $10 \mathrm{~cm}$ wide and $10 \mathrm{~cm}$ long, pockets were made with aluminum foil, and the pieces of $\alpha$-cellulose paper were installed in the pockets (Kim et al., 2011). An area of $50 \mathrm{~cm}^{2}$ at the front end of each aluminum foil pocket was made so as to be exposed, and six pockets were connected together and installed on each apple tree (Fig. 1). The patches were installed at individual positions before pesticide was sprayed and were collected after the pesticide had been sprayed, and they were kept at $-20^{\circ} \mathrm{C}$ until the amounts of active ingredients of the pesticides could be analyzed. The analysis was conducted by the Dept. of Bio Environmental Chemistry, Chungnam National University, using the analytical instruments HPLC Hewlett Packard 1090 (USA) and LC/MS Shimadzu 2020 (Japan) by weighing the patches after removing the aluminum foil pockets. In the present paper, data regarding analysis conditions and calibration curve preparation and the results of recovery rate tests have been omitted, and only the results of the analysis of the amounts of active ingredients attached are presented. After pesticide was sprayed, the flypaper in the pheromone traps was col- lected, whether the density had changed was checked, and the resultant amounts of active ingredients per unit area from patch analysis and the capture density of the pheromone traps were compared to identify control effects. In the case of $A$. citricola, the control values on the third and seventh day after pesticide spraying were calculated, and their correlations with the amounts of active ingredients per unit area obtained by patch analysis were checked.

\section{RESULTS}

\section{Actual state of pesticide spray volumes using SSs for insect pest control in apple orchards}

The apple orchard in Shinpung, Gongju, Chungnam sprayed pesticides at least 12 times until early September, beginning with a pesticide spray in April for controlling moths and insect pests that had survived the winter. According to the results of a study conducted by Kwon et al. (2001), each fruit farm sprays pesticides 11 to 15.8 times per year, and in the case of apples, the number of spraying decreases year by year. In the case of the farm tested in the present study, pesticide sprayings for insect pest control were conducted customarily at intervals of 15 to 20 days regardless of whether insect pests had occurred or not. However, for the experiments to review the possibility of controlling spray volumes, four pesticide spray tests were conducted after identifying the occurrence of insect pests through moth monitoring pheromone traps and visual investigations. In these tests, the selections of pesticides for insect pest control, spray volumes, and spray methods were all made using the customary methods of apple orchard farmers. To identify the actual state of the use of pesticides in actual apple orchards, the number of times of sprays using the SS with a $500 \mathrm{l}$ tank and all the residual quantities of pesticides were identified to calculate spray volumes per unit area. The spray volumes according to kinds of crops presented by the criteria for pesticide registration and tests for safe pesticide spray methods have been determined according to the kinds of crops regardless of cultivation time or the times of occurrence of insect pests, such as $4,5001 /$ ha in the case of apples (Hong et al., 2013). Lee et al. (2007) reported that approximately $60 \%$ of apple farms that sprayed pesticides using SSs sprayed 300$4001 / 10 \mathrm{a}$ and that the average spray volume per unit area was approximately $3601 / 10 \mathrm{a}$. As can be seen in Table 1, on average, $17 \mathrm{P}$. ringoniella and $G$. molesta
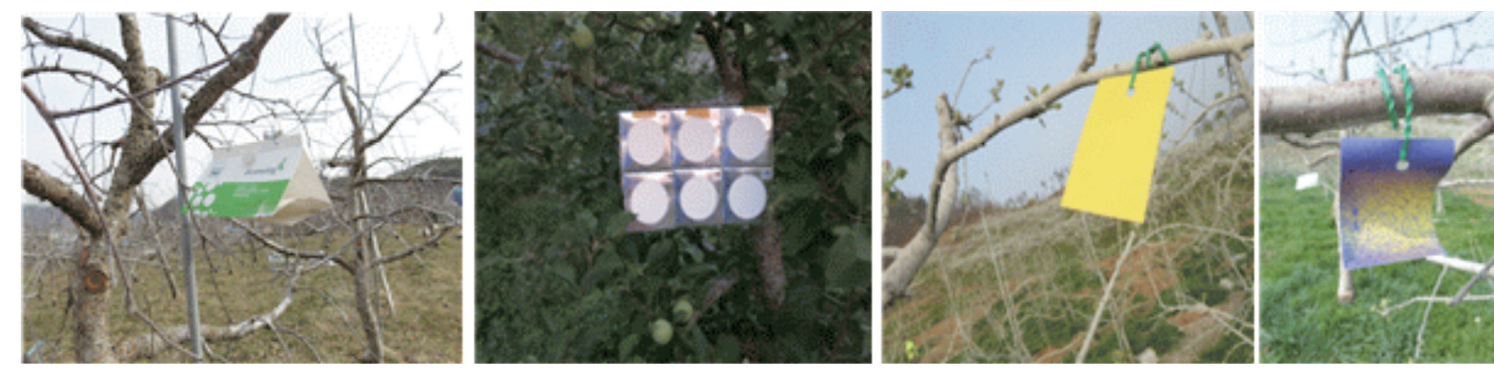

Fig. 1. Pheromone trap, $\alpha$-cellulose paper patch, water sensitive paper. 
were captured per trap in the middle of April, and thus 372 1/10 a of acetamiprid 8\% water dispersible powder was sprayed for moth control. Since the trees had no leaves or fruits because the flowers had not yet bloomed, the spray volume was less than the standard volume. However, when pesticides were sprayed three times thereafter between June and late August for A. citricola and moth control, spray volumes of approximately 449452 1/10 a, which are close to the standard spray volume, were identified to have been sprayed. In general, other apple farms also adjust the spray volumes used according to cultivation times, as with the apple orchard in Gongju used in the present study, and it is considered necessary to review the possibility of adjusting pesticide spray volumes according to crop conditions. However, pesticide spray volumes can be an important factor in terms of disease and insect pest control effects. Lee et al. (2007) pointed to insufficient spray volumes as the largest cause of inefficient disease and insect pest control effects, indicating that approximately $48 \%$ of cases of inefficient disease and insect pest control effects were due to insufficient spray volumes and stated that dense planting and low pesticide use could also be causes of inefficient disease and insect pest control effects. Therefore, efficient insect pest control effects were judged to be achievable not just by increasing spray volumes but by also standardizing the kinds of sprayers and spray methods (Son et al., 2012).

\section{Spray time, spray velocity, and spray pressure}

Pesticide spray time is the most important factor in calculating farm workers' exposure to pesticides, and the UK-POEM that is used as a model for the calculation of farm workers' exposure to pesticides in fruit farms in South Korea recommends working for not more than six hours up to 4 ha per day (Hong et al., 2007). When converted using $10 \mathrm{a}$ as the unit area, this value becomes a spray time of approximately nine minutes per unit area. The pesticide sprays in the apple orchard in Gongju had spray times of 18 to 28 minutes per unit area $(10 \mathrm{a})$, and the shortest spray time was identified from a spraying of 3721 per 10 a in the middle of April when spray volumes were small (Table 1). Spray time may vary according to not only spray volume but also planting density, the topography of apple orchards, the growth conditions of crops, and the degree of occurrence of diseases or insect pests. The longest spray time per unit area for the same spray volume, which appeared in late August when the fruit were ripening and growing bigger and many $G$. molesta and $P$. ringoniella occurred according to the high capture densities per trap, seems to be attributable to those factors. These problems are considered soluble by adjusting spray solution particle sizes, spray velocity, or spray pressure after solving mechanical problems in the sprayer or nozzles. In the present study, using SSs installed with two types of nozzles - $0.2 \mathrm{~mm}$ nozzles at the inside and $1.2 \mathrm{~mm}$ nozzles at the outside - farm workers sprayed pesticides while autonomously adjusting spray velocity between low velocity 2-3 levels and spray pressure in the range of 2,000 2,500 rpm. Since most farm workers were found to freely adjust spray velocity and spray pressure based on the heights of crops and fruit farm conditions, standardizing spray velocity and spray pressure seemed to be difficult. Therefore, additional surveys are considered necessary for spray methods and the amounts of active ingredients used on crops according to the kinds of nozzles used.

\section{Amounts of active ingredients of pesticides per unit area according to spray volumes and cultiva- tion time}

Through four times of pesticide sprayings between April and August, it was identified that spray volumes per unit area varied with cultivation time. In fact, as mentioned above, the spray volumes according to kinds of crops presented by the criteria for pesticide registration and tests for safe pesticide spray methods have been determined according to the kinds of crops regardless of cultivation time or the times of occurrence of insect pests, such as 4,500 1/ha in the case of apples. In the present study, among the three times of pesticide spraying for control of $G$. molesta and $P$. ringoniella, whereas approximately 372 1/10 a of pesticides were sprayed in the middle of April, which was before the flowering time, $449 \mathrm{l} / 10 \mathrm{a}$ and $452 \mathrm{l} / 10 \mathrm{a}$ of pesticides were sprayed in July and August, respectively, when the trees had leaves and fruits, indicating differences according to cultivation time. These differences in spray volumes may also affect the amounts of active ingredients used per unit area, thereby affecting disease and insect pest control effects. The amounts of active ingredients used according to spray volumes were examined through the analysis of patches in survey plots. As can be seen in Table 2, when $372 / 10$ a of pesticides were sprayed in the middle of April when the trees had no leaf or fruit, the amounts of active ingredients showed statistically significant differences among plots as the values varied in the range of $57.62-71.35 \mu \mathrm{g} / 50 \mathrm{~cm}^{2}$ patch area. When converted for unit area, the values are shown to be approximately $0.12-0.34 \mathrm{~kg}$ a.i. $/ 10$ a. Since the acetamiprid $8 \%$ water dispersible powder sprayed in the middle of April is known to show fatality rates of at least $95 \%$ when the amount of the active ingredients per the unit area is $0.018 \mathrm{~kg}$ a.i./10 a or higher, insect pest control effects can be sufficiently identified if the spray volume reaches 400 l/10 a. However, in this test, although the spray volume was reduced to approximately $3701 / 10 \mathrm{a}$, the amounts of active ingredients per unit area were identified as being sufficient to kill at least $95 \%$ of insect pests. In the pesticide spray test conducted on July 28, when dinotefuran $20 \%$ granular water dispersible powder was sprayed in a spray volume of $449 \mathrm{l} / 10 \mathrm{a}$, the amounts of active ingredients attached to the patches installed in individual plots did not show large differences from the results of the pesticide spray test conducted in the middle of April, and the active ingredients were sprayed relatively uniformly among the plots with average values in the range of $53.10-73.27 \mu \mathrm{g} / 50 \mathrm{~cm}^{2}$. When converted into amounts of active ingredients per unit area, these values become $0.11-0.15 \mathrm{~kg}$ a.i./10 a, indicating that larger 
amounts than the amount of active ingredients for $\mathrm{LC}_{95}$ at $0.080 \mathrm{~kg}$ a.i./10 a were sprayed in all plots. However, since differences in the amounts of active ingredients attached were large in each plot, points that were treated with amounts below the amount of active ingredients, necessary to show the efficacy of the chemicals, were identified in all three plots. In the pesticide spray test conducted in late August, pesticides were sprayed with a spray volume of $452 \mathrm{l} / 10 \mathrm{a}$, and the pesticides were not uniformly sprayed - to the extent that differences in the amounts of active ingredients among plots showed statistically significant differences from those in the tests conducted in April and July. In one plot, the average amount of active ingredients was $0.06 \mathrm{~kg}$ a.i./10 a, which was much lower than the amount of active ingredients for $\mathrm{LC}_{95}$ at $0.160 \mathrm{~kg}$ a.i. $/ 10 \mathrm{a}$, while in the remaining two plots, pesticides were sprayed in amounts more than necessary, with the amounts of active ingredients used in the range of $0.61-0.71 \mathrm{~kg}$ a.i./10 a. Therefore, the possibility of reducing spray volumes in cases where uniform sprays are possible was sufficiently identified (Table 2).

Although the results of the spray of acetamiprid $2.5 \%$ and etofenprox $8 \%$ water dispersible powder in a spray volume of $452 \mathrm{l} / 10$ a in the middle of June for control of $A$. citricola showed differences in the amounts of active ingredients used in the range of $0.00-0.20 \mathrm{~kg}$ a.i./10 a among the plots, the differences were not statistically significant $(p=0.089)$. Even before the analysis of the amounts used, the degree of pesticide sprays could be identified through the degree of coating on the water sensitive paper. Three survey plots with a poor coating of the pesticides on the water sensitive paper showed smaller amounts of active ingredients compared to other plots (Table 3, plots A, B, and D). In this test, although sufficient volumes of pesticides were sprayed, the amounts of active ingredients used in two survey plots (plots B and C) did not reach $0.01 \mathrm{~kg}$, which is the amount of active ingredients that can achieve $\mathrm{LC}_{95}$, but they were identified as almost being below the detection limit, indicating that active ingredients' treatment efficiency cannot be enhanced simply by increasing spray volumes (Table 3). The results of a study conducted by Ha et al. (2012) reported the annual amount of pesticides used per unit area of apple orchards as $11.7 \mathrm{~kg}$ a.i./10 a. In the results of the present study, upon reviewing the amounts of active ingredients achieved through four rounds of pesticide sprays, it can be seen that the amount of active ingredients reached $1.41 \mathrm{~kg}$ a.i./10 a at the maximum. Therefore, if it is assumed that pesticides are sprayed 12 to 15 times per year, the amount of active ingredients can be regarded to reach $4.23-5.64 \mathrm{~kg}$ a.i./10 a per year. Ihm et al. (2003) stated that the amount of agrochemicals used per unit area when apples were being cultivated was approximately $22.1 \mathrm{~kg}$ a.i./10 a, and out of that amount, the amount of pesticides used was approximately $6.9 \mathrm{~kg}$ a.i./10 a. If the amount of pesticides used has been decreased by approximately 50\% today, when viewed from the aspect of the amount of pesticide used

Table 2. Spray volume (L/10 a), actual amount of active ingredient (a.i. kg/10 a), number of moths (G. molesta and P. ringoniella) per a trap depending on the cultivation time after treatment of each insecticide

\begin{tabular}{|c|c|c|c|c|c|c|c|c|}
\hline \multirow{2}{*}{ Date } & \multirow{2}{*}{$1 / 10 \mathrm{a}$} & \multirow{2}{*}{ plots } & \multicolumn{3}{|c|}{ Amount of active ingredient } & \multicolumn{3}{|c|}{$\begin{array}{l}\text { Mean moths captured per a trap } \\
\text { after treatments }\end{array}$} \\
\hline & & & $\mu \mathrm{g} / 50 \mathrm{~cm}^{2}$ patch & kg a.i./10 a & $\begin{array}{l}\mathrm{kg} \mathrm{a.i} / 10 \mathrm{a} \\
\text { for } \mathrm{LC}_{95}\end{array}$ & Before & 3 day & 15 day \\
\hline \multirow{4}{*}{$\begin{array}{l}\text { Apr. } 15^{1)} \\
(-)^{*}\end{array}$} & \multirow{4}{*}{372} & A & $\begin{array}{c}171.35 \\
(163.47-179.22)\end{array}$ & $\begin{array}{l}0.34 \pm 0.02 c \\
(0.33-0.36)\end{array}$ & \multirow{4}{*}{0.018} & 17 & 2 & 3 \\
\hline & & B & $\begin{array}{c}140.41 \\
(135.58-145.24)\end{array}$ & $\begin{array}{l}0.28 \pm 0.01 b \\
(0.27-0.29)\end{array}$ & & 18 & 3 & 9 \\
\hline & & \multirow[t]{2}{*}{ C } & $\begin{array}{c}57.62 \\
(54.15-61.08)\end{array}$ & $\begin{array}{l}0.12 \pm 0.01 \mathrm{a} \\
(0.11-0.12)\end{array}$ & & 15 & 5 & 7 \\
\hline & & & $P^{4)}$ & 0.000 & & & & \\
\hline \multirow{4}{*}{$\begin{array}{c}\text { Jul. } 28^{2)} \\
\text { (leaves and } \\
\text { fruit) }\end{array}$} & \multirow{4}{*}{449} & A & $\begin{array}{c}73.27 \\
(25.56-149.79)\end{array}$ & $\begin{array}{l}0.15 \pm 0.08 \mathrm{a} \\
(0.05-0.28)\end{array}$ & \multirow{4}{*}{0.080} & 30 & 2 & 26 \\
\hline & & B & $\begin{array}{c}63.40 \\
(6.15-164.86)\end{array}$ & $\begin{array}{l}0.13 \pm 0.09 \mathrm{a} \\
(0.01-0.33)\end{array}$ & & 12 & 3 & 14 \\
\hline & & $\mathrm{C}$ & $\begin{array}{c}53.10 \\
(29.03-93.09)\end{array}$ & $\begin{array}{l}0.11 \pm 0.04 \mathrm{a} \\
(0.07-0.19)\end{array}$ & & 4 & 3 & 20 \\
\hline & & & $P^{4)}$ & 0.184 & & & & \\
\hline \multirow{4}{*}{$\begin{array}{l}\text { Aug. } 28^{3)} \\
\text { (leaves and } \\
\text { fruit) }\end{array}$} & \multirow{4}{*}{452} & A & $\begin{array}{c}434.73 \\
(36.51-927.78)\end{array}$ & $\begin{array}{l}0.87 \pm 0.63 b \\
(0.07-1.86)\end{array}$ & \multirow{4}{*}{0.160} & 31 & 6 & 9 \\
\hline & & B & $\begin{array}{c}383.74 \\
(83.39-698.43)\end{array}$ & $\begin{array}{l}0.77 \pm 0.52 b \\
(0.17-1.59)\end{array}$ & & 48 & 44 & 58 \\
\hline & & \multirow[t]{2}{*}{$\mathrm{C}$} & $\begin{array}{c}28.67 \\
(3.22-195.86) \\
\end{array}$ & $\begin{array}{l}0.06 \pm 0.11 \mathrm{a} \\
(0.01-0.39)\end{array}$ & & 46 & 12 & 92 \\
\hline & & & $P^{4)}$ & 0.000 & & & & \\
\hline
\end{tabular}

* This period has no leaves or fruit on the apple trees.

${ }^{1)}$ acetamiprid 8\% WP ; ${ }^{2)}$ dinotefuran 20\% WG ; ${ }^{3)}$ thiodicarb 40\% WP.

4) One-way ANOVA, Post hoc tests by Duncan in SPSS version. 
Table 3. Control effects against $A$. citricola according to the amount of acetamiprid $2.5 \% \mathrm{WP}$

\begin{tabular}{|c|c|c|c|c|c|c|}
\hline \multirow[t]{2}{*}{ Plots } & \multirow{2}{*}{$\begin{array}{l}\text { No. of aphids } \\
\text { per plot before } \\
\text { treatment }\end{array}$} & \multirow{2}{*}{$\begin{array}{l}\text { Coverage grade } \\
\text { of WSP }{ }^{1)}\end{array}$} & \multicolumn{2}{|c|}{$\begin{array}{l}\text { amount of acetamiprid } \\
\left(\mu \mathrm{g} / 50 \mathrm{~cm}^{2} \text { patch }\right)\end{array}$} & \multicolumn{2}{|c|}{ Control value (\%) } \\
\hline & & & $\mu \mathrm{g} / 50 \mathrm{~cm}^{2}$ patch & kg a.i./10 a & 3 day & 7 day \\
\hline $\mathrm{A}$ & 92.3 & $\mathrm{P}$ & $\begin{array}{l}2.63 \pm 2.07 \\
(0.44-5.3)\end{array}$ & $\begin{array}{l}0.01 \pm 0.00 \mathrm{a} \\
(0.00-0.01)\end{array}$ & 100 & 100 \\
\hline B & 153.6 & $\mathrm{P}$ & $>0.0005$ & $0.00 \pm 0.00 \mathrm{a}$ & 78.1 & 78.5 \\
\hline $\mathrm{C}$ & 95.0 & G & $\begin{array}{c}24.6 \pm 37.11 \\
(5.59-100.04)\end{array}$ & $\begin{array}{l}0.05 \pm 0.07 \mathrm{~b} \\
(0.01-0.20)\end{array}$ & 100 & 100 \\
\hline $\mathrm{D}$ & 255.3 & $\mathrm{P}$ & $\begin{array}{c}2.13 \\
(>0.0005-5.18)\end{array}$ & $0.00 \pm 0.00 \mathrm{a}$ & 77.6 & 79.8 \\
\hline $\mathrm{E}$ & 54.3 & G & $\begin{array}{l}18.40 \pm 14.02 \\
(5.55-44.71)\end{array}$ & $\begin{array}{c}0.04 \pm 0.03 \mathrm{ab} \\
(0.01-0.09)\end{array}$ & 100 & 100 \\
\hline $\mathrm{F}$ & 69.6 & G & $\begin{array}{c}10.42 \pm 7.38 \\
(4.22-24.93)\end{array}$ & $\begin{array}{c}0.02 \pm 0.01 \mathrm{ab} \\
(0.01-0.05)\end{array}$ & 88.5 & 100 \\
\hline G & 273.0 & G & $\begin{array}{c}13.6 \pm 12.8 \\
(5.92-38.76)\end{array}$ & $\begin{array}{c}0.03 \pm 0.03 \mathrm{ab} \\
(0.01-0.08)\end{array}$ & 100 & 100 \\
\hline $\mathrm{H}$ & 104.0 & G & $\begin{array}{l}12.63 \pm 12.03 \\
(2.64-28.68)\end{array}$ & $\begin{array}{c}0.03 \pm 0.02 \mathrm{ab} \\
(0.01-0.06)\end{array}$ & 100 & 100 \\
\hline & & & $p^{2)}$ & 0.089 & & \\
\hline
\end{tabular}

${ }^{1)}$ WSP: Water Sensitive Paper, G: Good ; P: Poor.

2) One-way ANOVA, Post hoc tests by Duncan in SPSS version.

per unit area, the amount of pesticides used per unit area in the apple orchard in the present study is judged to be too large.

\section{Insect pest control effects according to the amounts of active ingredients}

The amounts of active ingredients of pesticide by plot were surveyed through patches and attempts were made to identify insect pest control effects according to the amounts of active ingredients used. Insect pests occurring in apples show some differences according to cultural patterns and the degree of use of pesticides. Although Tortricinae moths were a major problem until the 1990 s, moth insect pests such as $P$. ringoniella and $G$. molesta, which had caused few problems previously, have been occurring as major insect pests since the late 1990s (Choi et al., 2004). In addition, although $G$. molesta had required less control compared to Carposina sasakii, recently, it has been causing serious fruit damage in chief apple producing regions (Choi et al., 2008). In the farm surveyed in the present study, G. molesta and $P$. ringoniella were captured by pheromone traps from early April — o damage could be expected — and three tests were conducted in relation to pesticide sprays for moth control. After all three rounds of pesticide sprayings, as a result of control effects, when the amounts of active ingredients used were larger, the densities of $G$. molesta and $P$. ringoniella captured per pheromone trap after pesticide sprays were lower. In April and July, pesticides were sprayed when the densities of insect pests captured by the traps were 4 to 30 per trap on average, depending on the amounts of active ingredients per patch area. The capture density per trap decreased to $2-3$ on the third day after spraying in both cases but increased when 15 days had passed after pesticide spraying in both cases (Fig. 2. A and B). The tendency of cap- ture densities to first decrease and increase thereafter appeared remarkable in plots where the amounts of active ingredients attached to patches were relatively small (Fig. $2 \mathrm{~A}$ and C). However, as can be seen in Table 2, the amounts of active ingredients were not different among the three plots after the dinotefuran $20 \%$ granular water dispersible powder pesticide was sprayed in the middle of July, and, accordingly, the densities of moths captured by the traps did not show any big difference. On the other hand, the thiodicarb 40\% water dispersible powder sprayed in late August showed clear differences in the amounts of active ingredients among treatment plots. Not only were there decreases in the density of insect pests after pesticide spraying, but rapid increases in the density of insect pests were also shown to be relatively larger in plots where the amounts of active ingredients attached were smaller (Fig. 2 C).

The insect pest control effects according to the amounts of active ingredients used as such appeared not only in moth control but also in the results of the control of $A$. citricola. Table 3 presents the control effects on the third and seventh days after acetamiprid $2.5 \%$ and etofenprox $8 \%$ water dispersible powder sprayings in the middle of June for the control of $A$. citricola along with the results according to the amounts of active ingredients by treated plot. In the case of the pesticide used in this test, the appropriate amount of active ingredients that can generally achieve $\mathrm{LC}_{95}$ is approximately $0.01 \mathrm{~kg}$ a.i. $/ 10 \mathrm{a}$. Among the eight survey plots, two plots, B and C, showed almost no amount of active ingredients, with an average value of $0.00 \mathrm{~kg}$ a.i. $/ 10 \mathrm{a}$, and these two plots showed control values of 78.5 and $79.8 \%$, respectively, even on the seventh day after the pesticide spraying. Plot F showed a control value of $88.5 \%$ on the third day after the pesticide spraying probably because the amounts of active ingredients in this plot were small, with an average value 


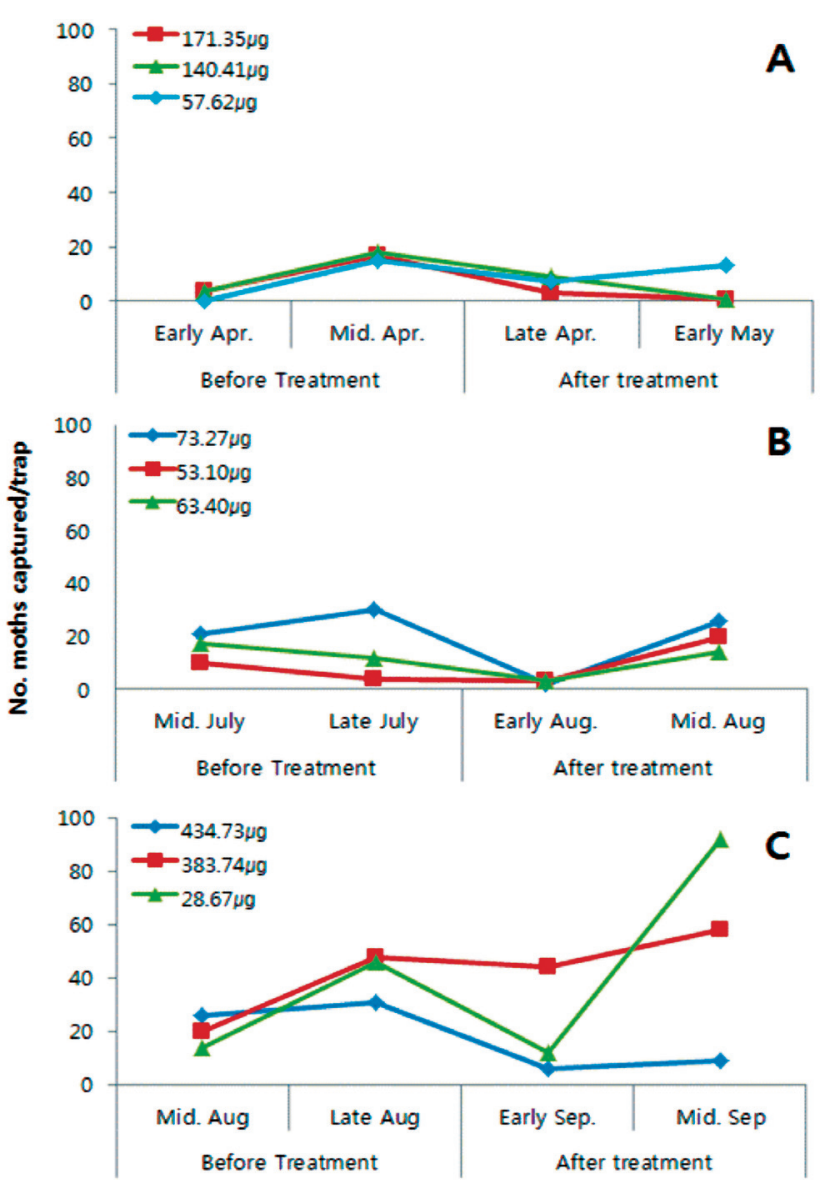

Fig. 2. Number of moths (G. molesta and P. ringoniella) per a trap according to the amount of active ingredient $\left(\mu \mathrm{g} / 50 \mathrm{~cm}^{2}\right)$ per patch after treatment with each insecticide (A: acetamiprid 8\% WP; B: dinotefuran 20\% WG; C: thiodicarb 40\% WP).

of 0.02 , but they showed a control value of $100 \%$, identical to other plots on the seventh day after the pesticide spraying (Table 3). The correlation between the amounts of active ingredients per unit area and the A. citricola control effects was evaluated, and the results showed that as the amounts of active ingredients increased, the control effects also increased. In particular, when the amount of active ingredients was $0.01 \mathrm{~kg}$ a.i./10 a or larger, control values of not lower than 90\% could be obtained against $A$. citricola (Fig. 3 ).

There have been few study results regarding insect pest control effects according to the amount of pesticide used per unit area or the amounts of active ingredients used. In the results of the present study, non-uniform pesticide sprays, which result in large differences in the amount of pesticide used per unit area among treated plots even when spray volumes are sufficient, were the largest problem. In the farm surveyed in the present study, also, although pesticides were sprayed within the volumes determined by the standard pesticide spray methods, plots that were treated with amounts below the target amounts of active ingredients that can affect control effects appeared. These plots play the role of hiding places or refuges for insect pests to increases in density

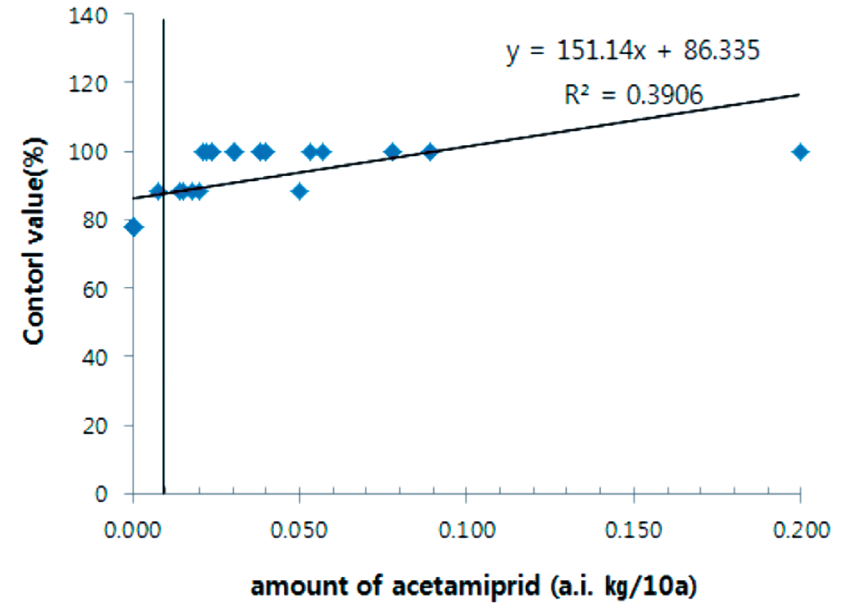

Fig. 3. Correlation between amount of acetamiprid (kg a.i./10 a) and control value against $A$. citricola.

after control efforts. In addition, some spray plots were treated with amounts of active ingredients larger than is necessary. Therefore, the possibility of adjusting spray volumes according to cultivation times through the standardization of spray methods that can enable uniform sprays was sufficiently identified.

\section{ACKNOWLEDGEMENTS}

This paper was prepared based on the results obtained in the process of performing the task [Standardization of spraying equipment and methods and grouping of containers and formulation in using pesticide, PJ010043] under the joint research project of the Rural Development Administration.

\section{REFERENCES}

Choi, K. H., S. W. Lee, D. H. Lee, D. A. Kim and S. K. Kim 2008 Recent occurrence status of two major fruit moths, oriental fruit moth and peach fruit moth in apple orchards. Kor. J. Appl. Entomol., 47: 17-22

Choi, K. H., S. W. Lee, D. H. Lee, D. A. Kim, S. J. Suh and Y. J. Kwon 2004 Recent occurrence status of Tortricidae pests in apple orchards in Geongbuk province. Kor. J. Appl. Entomol., 43: 189-194

Ha, H. Y., D. S. Ra, W. C. Shin, G. J. Im and J. Park 2012 Survey of pesticide use in fruit vegetables, fruits, and rice cultivation areas in Korea. Kor. J. Pesticide Sci., 16: 395-400

Hong, S., J. B. Lee, Y. K. Park, J. S. Shin, G. J. Im and G. H. Ryu 2007 The proposal for pesticide exposure estimation of Korean orchard farmer. Kor. J. Pesticide Sci., 11: 281-288

Hong, S, A. S. You, M. Jeong, K. H. Park, J. Y. Park and Y. J. Lee 2013 Risk assessment of pesticide operator using modified UK-POEM in Korean orchards. Kor. J. Pesticide Sci., 17: 50-59

Ihm, Y. B., K. S. Kim, K. S. Kyung, N. S. Kim, H. Y. Ha, H. D. Lee, K. S. Oh, J. W. Kim and G. H. Ryu 2003 Survey of pesticide usage on fruits in Korea. Kor. J. Pest. Sci., 7: 258-263

Jeong, Y. H., J. E. Kim, J. H. Kim, Y. D. Lee, C. H. Lim and J. H. Hur 2004 Pesticide use: The latest pesticide studies, $2^{\text {nd }}$ ed. Sigmapress, Seoul

Kim, E., H. Lee, H. H. Choi, J. K. Moon, S. Hong, M. Jeong, K. H. Park, H. Lee, A. X. Hua and J. H. Kim 2011 Methods valida- 
tion for monitoring of agricultural worker exposure to insecticide fenthion. Kor. J. Pest. Sci., 15: 357-365

Kwon, O. K., S. M. Hong, D. S. Choi, C. W. Park, B. H. Song, G. H. Ryu and B.Y. Oh 2001 Survey of pesticide usage on fruit crops for the development of pesticide use indicator. Kor. J. Pest. Sci., 5: 40-44

Lee, S. W., D. H. Lee, K. H. Choi and D. A. Kim 2007 A report on current management of major apple pests based on census data from farmers. Kor. J. Hort. Sci. Technol., 25: 196-203

Son, K. A., T. K. Kang, B. J. Park, T. K. Kim, G. H. Gil, C. S. Kim, J. B. Kim, G. J. Im and K. W. Lee 2012 Effect of field location and spray device on pesticide residue in chili peppers. Kor. J. Pest. Sci., 16: 230-235 